\title{
IMPROVING THE DRUG COMPLIANCE OF HYPERTENSIVE PATIENTS IN PRIMARY CARE: IMPORTANCE OF HEALTH EDUCATION AND SELF-MANAGEMENT
}

\author{
Oleksii KORZH ${ }^{1 凶}$, Sergiy KRASNOKUTSKIY' ${ }^{1}$, Olena PANKOVA ${ }^{1}$ \\ ${ }^{1}$ Kharkiv Medical Academy of Postgraduate Education, Department of General Practice-Family Medicine, \\ Kharkiv, Ukraine
}

Received 23 Apr 2019, Accepted 07 July 2019

hitps://doi.org/10.31688/ABMU.2019.54.3.15

\begin{abstract}
Introduction. Given the prevalence and burden of arterial hypertension, it is necessary to obtain an optimal control of blood pressure in order to improve the prognosis of these patients. Adherence to antihypertensive therapy is poor, leading to non-optimal disease control.
\end{abstract}

The objective of the study was to investigate the adherence to therapy in hypertensive patients and to assess the impact of health education and self-action plan in improving the compliance to the therapy in primary care settings.

Material and methods. A prospective study was conducted in 750 patients diagnosed with primary hypertension for 3 years. After inclusion in the study, patients were monitored for 24 weeks to evaluate treatment non-compliance. In patients without adherence to antihypertensive therapy, we used various health education strategies to improve compliance.

Results. A total of 750 patients with essential hypertension who started therapy over duration of 3 years were included in the study. At the end of 24 weeks, it was observed that only 324 patients $(43.2 \%)$ had regular compliance and 426 patients (56.8\%) were

\section{Résumé}

L'amélioration de la compliance à la médication chez les patients hypertendus dans les soins de santé primaires: importance de l'éducation à la santé et de l'auto-gestion

Introduction. Compte tenu de la prévalence et de la charge associée de l'hypertension, il est nécessaire d'obtenir un contrôle optimal de la pression artérielle et d'améliorer les résultats pour ces patients. Mais il a été noté que l'observation du traitement antihypertenseur est très mauvaise, conduisant à un contrôle non optimal de la maladie.

Le but de cette étude était d'investiguer l'observation thérapeutique des patients hypertendus et d'évaluer l'impact de l'éducation à la santé et du plan d'action sur l'amélioration de la compliance aux traitements dans les établissements de soins de santé primaires.

Matériel et méthodes. Une étude prospective a été menée chez 750 patients souffrant d'hypertension essentielle pendant 3 ans. Après l'inclusion à l'étude, les patients ont été surveillés pendant 24 semaines afin d'évaluer le manque de réponse au traitement. Chez les 
noncompliant to antihypertensive treatment. The factors that were associated with poor compliance were: a low level of education, burdensome treatment, dislike of drugs, remote pharmacies, concerns about side effects, anger about the condition or its treatment, forgetfulness or complacency, as well as the patients' poor attitude to health. After employing various strategies for improving the compliance in these patients, the compliance increased in 263 patients (61.7\%) among the earlier defaulted patients, while the remaining 163 patients (38.3\%) were found to be noncompliant even after various educational techniques.

Conclusions. Failure to treat hypertension is a reality, and none of the strategies for improving compliance are likely to be as effective as a good doctor-patient relationship. Optimal self-management, which allows to optimize control of arterial hypertension by adjusting drugs, can be carried out by self-regulation using a written plan of action or by regular medical examination.

Keywords: hypertension, compliance, health education, nonadherence, self-management.

\section{INTRODUCTION}

Hypertension is one of the most prevalent diseases nowadays. High blood pressure (BP) is associated with an increased risk of cardiovascular events, and therefore it is recommended to treat BP to a level that will protect against these adverse effects ${ }^{1,2}$. Non-compliance to antihypertensive drug treatment can lead to the development of alterations of the blood vessels walls, and can cause hypertrophy and hyperplasia associated with intimate fibrosis ${ }^{3,4}$. The problem of inconsistency is not new; patients suffering from chronic diseases, especially those with fluctuating or not having symptoms, such as hypertension, most likely do not follow the medical recommendations $s^{5,6}$.

Currently, the most convincing evidence for improved strategies for treating hypertension is patients ne respectant pas le traitement antihypertenseur, nous avons utilisé diverses stratégies d'éducation à la santé pour améliorer l'observance thérapeutique dans ces cas.

Résultats. Un total de 750 patients souffrant d'hypertension essentielle et ayant commencé le traitement depuis une durée de 3 ans ont été inclus à l'étude. À la fin de 24 semaines, il est à noter que seuls 324 patients $(43,2 \%)$ présentaient une compliance régulière et 426 patients $(56,8 \%)$ étaient non-compliants au traitement prescrit pour l'hypertension artérielle. Les facteurs associés à une mauvaise observance étaient les suivants: faible niveau d'éducation, traitement difficile, aversion pour les médicaments et pharmacies à grande distance. Les facteurs qui ont réduit l'observance étaient les suivants: préoccupations au sujet d'effets secondaires, colère pour la condition de son traitement, négligence ou satisfaction de soi, et attitude diminuée du patient à l'égard de la santé. Après avoir utilisé différentes stratégies, l'observance a augmenté chez 263 patients $(61,7 \%)$ parmi les patients ayant subi des échecs antérieurs, tandis que les 163 patients restants (38,3\%) se sont montrés non conformes même après diverses techniques pédagogiques.

Conclusions. Le fait de ne pas traiter l'hypertension artérielle est une réalité, et aucune des stratégies visant à améliorer la compliance ne sera probablement aussi efficace qu'une bonne relation médecin-patient. Lauto-gestion optimale, qui permet d'optimiser le contrôle de l'hypertension artérielle en adaptant les médicaments, peut être réalisée par auto-régulation à l'aide d'un plan d'action écrit ou par un examen médical régulier.

Mots-clés: hypertension artérielle, compliance, éducation à la santé, non-observance, gestion autonome.

obtained from evidence-based clinical trials using well-identified patient profiles. However, the practice of clinical medicine requires the provider to apply these results to a real population that includes personalized approaches to different patient groups, as determined by their medical status, as well as their socio-demographic characteristics ${ }^{7,8}$.

In addition, a good communication with patients, in order to understand their disease and its complications, can improve adherence to antihypertensive therapy. A strategy that includes dynamic collaboration between physician and patient, along with a more active participation of pharmacists to support treatment goals and patient motivation, can improve adherence to therapy ${ }^{9-12}$. This is important because an inadequate control of hypertension is associated 
with excessive use of medical resources and an increased risk of cardiovascular diseases ${ }^{13}$.

The OBJective OF THE STUDY was to investigate the adherence to therapy in hypertensive patients and to assess the impact of health education and self-action plan in improving the compliance to the therapy in primary care settings.

\section{Materials AND Methods}

The study included patients diagnosed with primary hypertension, older than 18 years. It was a prospective study conducted in the primary care centers of Kharkiv (clinical bases of Kharkiv Medical Academy of Postgraduate Education), Ukraine, between August 2016 and September 2018.

The study followed the international bioethical standards (European Convention Council on Human Rights and Biomedicine) and recommendations of the Committee on Bioethics of the Ministry of Health of Ukraine. All patients signed an informed consent to participate in the study. This study was approved by the Ethics Commission of Kharkiv Medical Academy of Postgraduate Education, Ministry of Health of Ukraine (Kharkiv, UA).

All patients were interviewed using a standard interview schedule and asked to keep a diary regarding the dosage of drugs. In addition to a detailed history, physical examination, and vital signs were measured during the first visit. All patients received treatment in accordance with the recommendations of the European Society of Hypertension [ESH] / European Society of Cardiology [ESC] 2013 guideline for the treatment of arterial hypertension. The antihypertensive treatment was prescribed by the family doctors. All patients were observed every 30 days for 24 weeks. At the end of 24 weeks, treatment compliance was calculated after examining the patient's diary and the frequency of hospital visits. Disease control was assessed by measuring the blood pressure and electrocardiogram (ECG). The corresponding day was defined as the day on which the prescribed number of tablets or capsules was taken each day. It was considered that the patient was adherent if he / she took more than $80 \%$ of the prescribed drugs during the study period.

The second step in this study was to increase the health education in non-adherent patients. We tried to improve compliance by introducing a patient's education program with the help of cardiologists. The various strategies used to educate patients included verbal praise, interactive communication skills, drug adaptation to the patient's routine, default information meetings about hypertension for patients, disseminating literature on hypertension and its effects in local languages and answering questions. At this stage, all patients who did not participate in the study were informed in detail about the state of health regarding hypertension, its condition, chronic disease and duration of treatment, the nature of rapid relief and long-term medications, as well as preventive aspects of the disease. All patients were asked to keep a diary of any symptoms occurring during this period. In addition, the attending physician provided an action plan for all inappropriate cases, explaining what to do in case of high blood pressure or during any deterioration, and when to call the doctor. This will help the patient to be more interactive and communicate better with the doctor. At the second stage, all patients were under observation for another 24 weeks. The final assessment was made only at the end of this period.

Statistical analysis: data are expressed as the mean (standard deviation (SD)). Comparison of parameters between two groups was done by Student's t-test. Comparisons among three groups were done by one-way analysis of variance (ANOVA) with Bonferroni's multiple comparison tests. Differences in frequency between compliance and noncompliance patients were assessed by the Chi-square test. A $P$ value of less than 0.05 was considered significant.

\section{Results}

A total of 750 patients were examined. The majority of patients (39\%) were in the age group of $31-40$ years. The ratio of men and women was $3: 2$. The majority of patients, $420(56 \%)$, had either primary or secondary education level, and $10 \%$ were illiterate.

At the end of 24 weeks, 324 patients (43.2\%) underwent regular therapy and did not miss a single dose, while the remaining 426 (56.8)\% did not comply with the requirements. Among male patients, regular compliance was observed in 191 patients, while 133 patients received regular therapy. A higher number of male patients missed more than 20 doses in 24 weeks (56.6\%) compared with female patients (43.3\%). There was a significant correlation between educational status and matching therapy.

Non-drug factors were major causes of non-attachment to antihypertensive therapy (Table 1). The main non-medical factors associated with poor compliance were: fear of drug side effects (19\%), high cost of therapy (14\%), a sense of well-being during treatment (13\%), and negligence on the part of patients (12\%). Other causes included forgetfulness or complacency and attitudes toward poor health, anger about the condition, etc. Drug-related causes of inconsistencies included awkward regimens (for 
Table 1. Causes of non-adherence to antihypertensive therapy.

\begin{tabular}{|c|c|}
\hline Factors & No. $(\%)$ \\
\hline \multicolumn{2}{|l|}{ Non drug-related factors } \\
\hline Fear about side effects & $145(19)$ \\
\hline Feeling of well-being & $96(13)$ \\
\hline Negligence on the part of patients & $91(12)$ \\
\hline Forgetfulness/complacency & $74(10)$ \\
\hline Ill-attitude towards chronic health condition & $62(8)$ \\
\hline Anger about condition & $45(6)$ \\
\hline \multicolumn{2}{|l|}{ Drug-related factors } \\
\hline Cost of therapy & $102(14)$ \\
\hline Awkward regimens & $75(10)$ \\
\hline Dislike for medications & $44(6)$ \\
\hline Distant pharmacies & $39(5)$ \\
\hline
\end{tabular}

Many patients had more than one reason for non-compliance

example, three times a day or a few drugs), dislike of drugs and remote pharmacies.

After 24 weeks of therapy, various strategies were used by the educator to improve patients' compliance with antihypertensive therapy, and these patients were followed up for another 24 weeks to evaluate the response to the intervention. We tried to train these hypertensive patients in a variety of ways to improve adherence. These modalities included: verbal praise $(12 \%)$, interactive communication skills (11\%), drug adaptation to the patient's routine (10\%), holding hypertension awareness meetings for patients by default $(12 \%)$, distribution of hypertension literature and its consequences in local languages (20\%), response to family concerns (10\%), and a written plan of independent actions (25\%) (Table 2).

After 24 weeks of therapy, it was noted that compliance improved in an additional 263 patients (61.7\%) who had not previously fulfilled their obligations. The remaining 163 patients $(38.3 \%)$ were still not attached to therapy. Improvement was observed in accordance with female patients (48.1\%) compared with male patients (26\%). It was also noted that direct interaction with patients or with families of patients improved compliance to a significant level.

\section{Discussion}

This study identifies a complex network of factors that may affect compliance behavior in a group of patients diagnosed with hypertension. At first glance, the results showed a negative attitude towards drugs, low awareness of the condition and dissatisfaction with clinical meetings as an obstacle to following treatment recommendation $\mathrm{s}^{14,15}$. Basically, these factors can be grouped into two categories: non drug-related and drug-related. Most of them have clear implications for patient management, as there are many opportunities to improve communication between the patient and the doctor. First, it is perhaps surprising to find that patients with a chronic disease, such as hypertension, do not have basic knowledge about it, such as its potential risks, and why it is important to follow the prescribed treatment even in the absence of symptoms.

The hypertensive patients usually are treated by family doctors, and, if so, adequate information should be provided to reduce the fear and anxiety arising from the use of medicines; consequently, this will improve compliance ${ }^{16,17}$. However, this study shows that in a normal clinical situation, patients often do not understand what they are told, and, moreover, without this primary basis, the patient cannot justify the need for therapy. This aspect of the doctor-patient relationship was discussed earlier, when doctors offered simple instructions several times, and yet the patient, mainly due to anxiety, did not receive the information ${ }^{18}$. This gives the doctor a unique responsibility and the opportunity to act not only as a diagnostician, but also as a qualified medical teacher. In this regard, focus group participants give priority to the empathic qualities of the doctor ${ }^{19,20}$.

Table 2. Strategies employed for health education and its impact on compliance.

\begin{tabular}{ccccc}
\hline Health education strategies & Total (\%) & $\begin{array}{c}\text { Compliant; } \\
\text { No. }(\%), \\
263(100)\end{array}$ & $\begin{array}{c}\text { Noncompliant; } \\
\text { No. (\%), } \\
163(100)\end{array}$ & P value \\
\hline Written action plan & $98(23)$ & $55(21)$ & $43(26)$ & 1.13 \\
Distribution of asthma literature in local languages & $105(25)$ & $69(26)$ & $36(22)$ & 0.08 \\
Hypertension awareness meetings & $54(13)$ & $30(11)$ & $24(15)$ & 0.94 \\
Verbal praise & $53(12)$ & $21(8)$ & $32(20)$ & 0.86 \\
Interactive communication skills & $48(11)$ & $39(15)$ & $9(6)$ & 0.01 \\
Answering to family worries & $45(11)$ & $30(11)$ & $15(9)$ & 0.16 \\
Tailoring medications to patients needs & $23(5)$ & $19(8)$ & $4(2)$ & 0.001 \\
\hline
\end{tabular}


This implies that there is a need for a new perspective on health care that goes beyond the biomedical side of medicine, and that doctors should interact more actively with their patients and be able to study the patient's understanding of the world. To achieve this goal, it was proposed to use interpersonal communication skills among medical workers ${ }^{21,22}$.

However, it can be argued that the time frame for consultation with the family doctor and the lack of resources are an obstacle to meeting individual needs. We believe that the integration of group visits to family practice can be a practical solution. Meeting several patients with a family doctor at the same time allows to a more efficient use of the consultation time of the family doctor and a better interaction with patients, since a group approach can facilitate communication, exchange of views with the doctor and, therefore, compliance ${ }^{23}$.

Complient patients better understood their illness and possible treatment options. Committed patients better understood their disease and possible ways to treat this disease. They also had great confidence that the current therapeutical management would keep their illness under control. Satisfaction and faith in treating physicians were found to be low among the less committed groups compared to the highly committed groups ${ }^{24}$.

Comorbidities are also important factors responsible for non-compliance to therapy. It is known that depression is a risk factor for non-adherence to treatment. In this study, specific questions about depression in the questionnaire were excluded because of the sensitivity of the topic and the concerns about the lack of patient response $e^{25}$. The recognition by the patient of the disease process and the recommended treatment, knowledge and faith in treatment, effective interaction between the patient and the doctor, and the rutinization of drug therapy are crucial ${ }^{26,27}$.

The main methods that have been proposed and tested to improve compliance include improved dosing schedules, patients' education, and improved communication between the doctor and patient. It is well known that less frequent dosages and simple schedules work best ${ }^{28}$. There is less certainty that patient's education and/ or provider's involvement are essential in the long run ${ }^{29,30}$. The following are considered to improve compliance: specific written instructions for patients, patients' diaries, physician's/ provider's interest, less frequent doses, long-acting drugs, a simplified dose schedule, and self-management. Patients' education plays an important role in improving adherence to treatment in chronic diseases, such as arterial hypertension. Therefore, every effort should be made to motivate these patients at each visit. Motivational interviewing is one of the approaches to shape patients' motivation for adherence.

\section{Conclusions}

The percentage of regular compliance to antihypertensive treatment in our study was $43.2 \%$, and non-compliance rate was $56.8 \%$, significantly higher. Regular compliance is an important aspect in the management and control of high blood pressure, so patients should be advised to take anti-hypertensive therapy regularly and for long-time. Patients who believe in the doctor and the prescribed method of treatment are more likely to adhere to treatment than patients who have a negative attitude towards treatment. Hypertensive patients should be offered education and written action plans, tailored to their individual needs - this is a reinforcement of previous recommendations.

The current results and analysis of our study with the participation of a relatively large number of participants in primary care facilities can provide resources for future BP management strategies that should improve the health of hypertensive patients. Using targeted, specific methods to assess adherence to treatment of hypertension is crucial.

\section{Compliance with Ethics Requirements:}

„The authors declare no conflict of interest regarding this article"

"The authors declare that all the procedures and experiments of this study respect the ethical standards in the Helsinki Declaration of 1975, as revised in 2008(5), as well as the national law. Informed consent was obtained from all the patients included in the study"

"No funding for this study"

\section{References}

1. Dorobantu M, Tautu OF, Dimulescu D, et al. Perspectives on hypertension's prevalence, treatment and control in a high cardiovascular risk East European country: data from the SEPHAR III survey. J Hypertens. 2017;35(1):1-11.

2. Walther D, Curjuric I, Dratva J, et al. High blood pressure: prevalence and adherence to guidelines in a population-based cohort. Swiss Med Wkly. 2016;146:w14323.

3. Diaconu C, Bartos D, Balaceanu A. Heart failure: risk factors and comorbidities in hypertensive patients. Cardiovascular Therapeutics 2012;30(Suppl 1).

4. Herttua K, Tabák AG, Martikainen P, Vahtera J, Kivimäki M. Adherence to antihypertensive therapy prior to the first presentation of stroke in hypertensive adults: population-based study. Eur Heart J. 2013;34(38):2933-2939.

5. Mancia G, Zambon A, Soranna D, Merlino L, Corrao G. Factors involved in the discontinuation of antihypertensive 
drug therapy: an analysis from real life data. J Hypertens. 2014;32(8):1708-1715.

6. Diaconu C, Balaceanu A, Bartos D. Diuretics, first-line antihypertensive agents: are they always safe in the elderly? Romanian Journal of Internal Medicine 2014;52(2):87-90.

7. Viera AJ, Cohen LW, Mitchell CM, Sloane PD. High blood pressure knowledge among primary care patients with known hypertension: a North Carolina Family Medicine Research Network (NC-FM-RN) study. J Am Board Family Med. 2008;21(4):300-8.

8. Fortuna RJ, Nagel AK, Rocco TA, Legette-Sobers S, Quigley DD. Patient's experience with care and its association with adherence to hypertension medications. Am J Hypertens. 2017;31(3):340-345.

9. Hedegaard U, Kjeldsen LJ, Pottegard A, et al. Improving medication adherence in patients with hypertension: a randomized trial. Am J Med. 2015;128(12):1351-1361.

10. Hadi N, Rostami-Gooran N. Determinant factors of medication compliance in hypertensive patients of Shiraz, Iran. Arch Iran Med. 2004;7(4):292-6.

11. Bungau S, Tit DM, Fodor K, et al. Aspects regarding the pharmaceutical waste management in Romania. Sustainability 2018;10(8):2788.

12. Tit DM, Bungau S, Nistor Cseppento C, Copolovici DM, Buhas C. Disposal of unused medicines resulting from home treatment in Romania. Journal of Environmental Protection and Ecology 2016;17(4):1425-1433.

13. Putnam W, Lawson B, Buhariwalla F, et al. Hypertension and type 2 diabetes: what family physicians can do to improve control of blood pressure - an observational study. BMC Fam Pract. 2011;12:86.

14. Schiffrin EL. The year in clinical hypertension from other pages. Am J Hypertens. 2018;31(2):136-138.

15. Pirasath S, Kumanan T, Guruparan M. A study on knowledge, awareness, and medication adherence in patients with hypertension from a tertiary care centre from northern Sri Lanka. Int J Hypertens. 2017;2017:9656450.

16. Balaceanu LA, Diaconu CC, Aron G. Comparison between clinical characteristics of hypertensive male patients with chronic heart failure. Journal of Hypertension. 2013;29(e-Supplement A).

17. Korzh O, Krasnokutskiy S. Significance of education and self-management support for patients with chronic heart failure in family physician practice. Fam Med Prim Care Rev 2016; 18(4): 432-436.
18. Diaconu C, Dediu G, Iancu M. Drug-induced arterial hypertension - a frequently ignored cause of secondary hypertension: a review. Acta Cardiologica 2018;73:6:511-517.

19. Hassan NB, Hasanah CI, Foong K, et al. Identification of psychosocial factors of noncompliance in hypertensive patients. J Hum Hypertens. 2006;20(1):23-29.

20. Hansell MW, Mann EM, Kirk JK. Hypertension treatment strategies for older adults. J Fam Pract. 2017;66(9):546-554.

21. Abegaz TM, Shehab A, Gebreyohannes EA, Bhagavathula AS, Elnour AA. Nonadherence to antihypertensive drugs. A systematic review and meta-analysis. Medicine (Baltimore). 2017;96(4):e5641.

22. Cegala DJ, Marinelli T, Post D. The effects of patient communication skills training on compliance. Arch Fam Med 2000;9:57-64.

23. Demoner MS, Ramos ERP, Pereira ER. Factors associated with adherence to antihypertensive treatment in a primary care unit. Acta Paulista Enfermagem. 2012;25(S1):27-34.

24. Osamor PE, Owumi BE. Factors associated with treatment compliance in hypertension in southwest Nigeria. J Health Popul Nutr. 2011;29(6):619-28.

25. Dimatteo MR, Lepper HS, Croghan TW. Depression is a risk factor for noncompliance with medical treatment: Metaanalysis of the effects of anxiety and depression on patient adherence. Arch Intern Med 2000;160:2101-7.

26. Tajeu GS, Kent ST, Kronish IM, et al. Trends in antihypertensive medication discontinuation and low adherence among Medicare beneficiaries initiating treatment from 2007 to 2012. Hypertension. 2016; 68(3):565-75.

27. Riekert KA, Butz AM, Eggleston PA, Huss K, Winkelstein M, Rand CS. Caregiver-physician medication concordance and undertreatment of asthma inner-city children. Pediatrics. 2003;111:E214-20.

28. Abudahish A, Bella H. Adherence of primary care physicians in Aseer region, Saudi Arabia to the National protocol for the Management of Asthma. East Mediterr Health J. 2010;16:171-5.

29. Ambaw AD, Alemie GA, W/Yohannes SM, Mengesha ZB. Adherence to antihypertensive treatment and associated factors among patients on follow up at University of Gondar Hospital, Northwest Ethiopia. BMC Public Health. 2012;12:282.

30. Matsumura $\mathrm{K}$, Arima $\mathrm{H}$, Tominaga $\mathrm{M}$, et al. Impact of antihypertensive medication adherence on blood pressure control in hypertension: the COMFORT study. QJM: monthly journal of the Association of Physicians. 2013; 106(10):909-14. 